\title{
Temporal Bone Involvement in Cherubism: Case Report
}

\author{
Luciana Cardoso FONSECA ${ }^{1}$ \\ João Batista de FREITAS ${ }^{1}$ \\ Pedro Hernane MACIEL ${ }^{2}$ \\ Marcelo Gusmão Paraiso CAVALCANTI ${ }^{3}$ \\ ${ }^{1}$ Department of Radiology, Pontificial Catholic University, Belo Horizonte, MG, Brazil \\ ${ }^{2}$ Private Radiologic Practice, Belo Horizonte, MG, Brazil \\ ${ }^{3}$ Department of Radiology, Faculty of Dentistry, University of São Paulo, São Paulo, SP, Brazil
}

\begin{abstract}
Cherubism is a rare benign hereditary fibro-osseous disease involving the mandible and maxilla. We report a case of cherubism in a 10year-old girl for which the panoramic radiograph was insufficient for diagnosis of the disease. Clinical, histological, and radiological findings were discussed. The CT was taken and it confirmed not only the involvement of the jaws but also of the temporal bone. This was not found in the conventional radiograph.
\end{abstract}

Key Words: cherubism, jaws, computed tomography, x-ray, dental radiograph.

\section{INTRODUCTION}

According to the World Health Organization classification, cherubism belongs to a group of nonneoplastic bone lesions that affect only the jaws (1). Cherubism was first described in 1933 by Jones who described a condition that affected three siblings, which was characterized by a marked fullness of the cheeks and jaws and a slight upturning of the eyes revealing a rim of white sclera beneath the iris giving the children a cherubic appearance. It appears to be a hereditary disease with an autosomal dominant pattern of inheritance, although several sporadic cases have been reported (2). Anderson and McCleden reviewed 65 cases from 21 families and suggested that the pattern of inheritance was autossomal dominant, with $100 \%$ penetrance in male family members and 50 to $70 \%$ penetrance in female fmembers (3). The lesions usually start in early childhood, affect both jaws and have a symmetric distribution. It begins to swell gradually until puberty. Although the condition is known to regress spontaneously at puberty, surgical management is sometimes required for cosmetic reasons (4).
It is said that cherubism affects only the jaws and indirectly the antrum and orbital floor. The remainder of the face, skull, and the rest of the skeleton are usually not involved (4). However, Davis et al. (5) reported some rare occurrences in other bones, i.e., ribs, humerus and femur. Ramon and Engelberg (6) proposed a grading system for cherubism based on involvement: grade 1 (involvement of both mandibular ascending rami; grade 2 (same as grade 1 plus involvement of both maxillary tuberosities); grade 3 (massive involvement of whole maxilla and mandible, except the condylar processes); grade 4 (same as grade 3 with involvement of the floor of the orbits causing orbital compression).

Cherubism is an important entity to review because it can achieve considerable size before it is detected, and it can produce severe facial deformity $(7,8)$. The purpose of this paper is to report a case of cherubism that involved not only the maxilla and mandible but also the temporal bone.

\section{CASE REPORT}

A 10-year-old girl presented to a dentist with a 


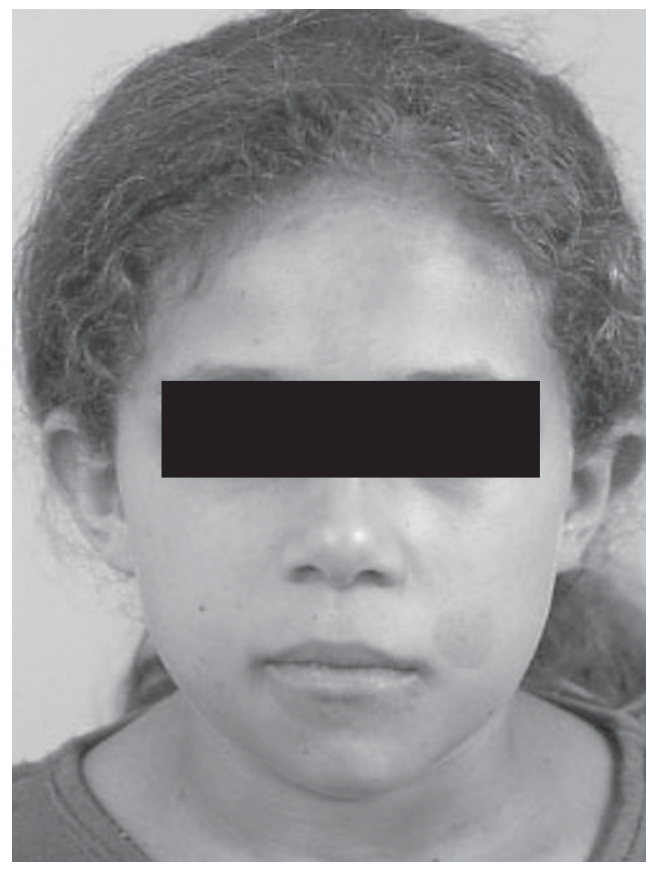

Figure 1. Facial appearance of the patient showing slight swelling of the left side of the face. slight swelling of the left side of the face (Figure 1). Intraorally, she had no alterations and the mucosa was normal. There were no symptoms and the medical history was unremarkable. The clinical laboratory values of serum calcium, phosphorous, parathormone and alkaline phosphatase were normal. There was no family history of a similar condition.

A panoramic radiograph showed extensive involvement of the mandible. Bilateral, multilocular, radiolucent lesions were found extending from the ascending ramus to the body of the mandible excluding the condyle region. The cortical borders were thinning and destroyed in some areas (Figure 2). The panoramic image was insufficient for studying the involvement of maxilla, thus a computed tomography can (CT) was done.

CT showed bilaterally multicystic bony lesions in the mandible and maxilla. Expansion and erosion in both cortices of the mandible were seen (Figure 3, left panel). The maxillary sinus was involved bilaterally by soft tissue (Figure 3, right panel). In addition, the lesion invaded the temporal bone of the left side causing
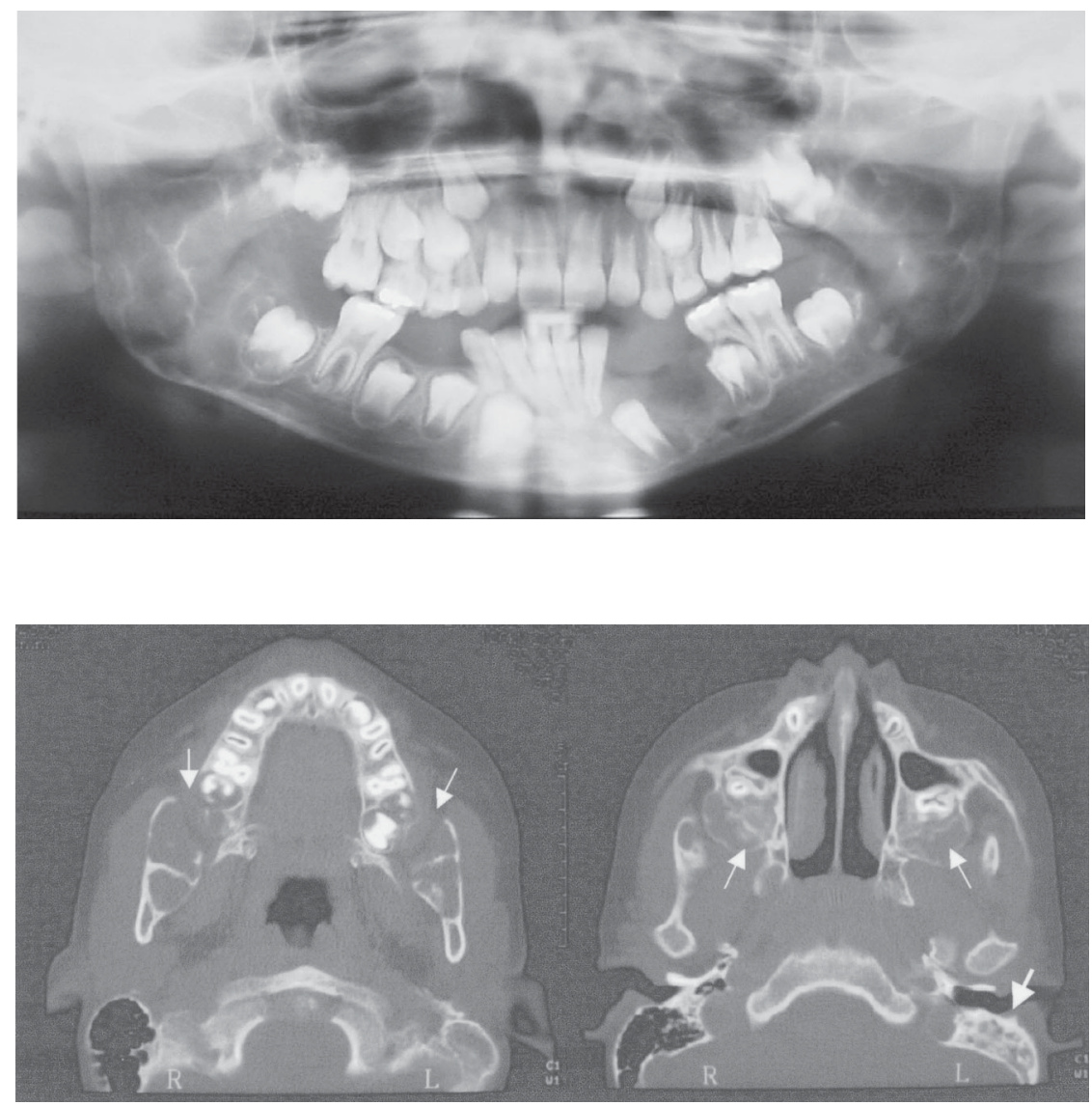

Figure 2. Panoramic radiograph showing multilocular lesions in the mandible. No sign of involvement of the maxilla.
Figure 3. Left panel: Axial CT scan of the mandible. Note the multicystic bony lesions, expansion and erosion in the cortices of the mandible (arrows). Right panel: Axial CT scan of the maxilla. Involvement of the lateral and posterior walls of the maxillary sinus bilaterally by the soft tissue and invasion of the temporal bone of the left side (arrows). 
changes of pneumatization of the mastoid cells (Figure 3 , right panel).

A biopsy showed dense cellular and fibrous vascular tissue with giant cells confirming the radiographic diagnosis of cherubism. Because there were no cosmetic or functional problems, the treatment included regular follow-up examinations.

\section{DISCUSSION}

A painless and bilateral expansion of the posterior mandible is the common early manifestation of cherubism. The lesions tend to involve the mandibular angles and ascending ramus. Lymphadenopathy has also been reported involving the submandibular area, and, more rarely, the upper cervical lymph nodes. It usually affects patients less than 5 years of age (9). In the present case, we could not find lymphadenopathy probably because the girl was older than 5 years of age. The patient had no significant swelling of the face that disagrees with the clinical aspects of cherubism.

Histologic examination of the lesions usually reveals numerous multinucleated giant cells. The collagenous stroma, which contains a large number of spindle-shaped fibroblasts, is considered unique because of its water-logged, granular nature. Numerous small vessels are present, and the capillaries exhibit large endothelial cells and perivascular capillary cuffing. The eosinophilic cuffing appears to be specific to cherubism. However, these deposits are not present in many cases, and their absence does not exclude the diagnosis of cherubism (10). A similar histological appearance is seen in central giant cell granuloma (CGCG), brown tumor of hyperparathyroidism and giant cell tumor (GCT). Histologically, we found proliferating fibrous tissue with giant cells confirming the diagnosis of cherubism.

The radiographic findings of cherubism are expansion of the lesions that often cause thinning of the cortex, and may cause obliteration of the maxillary sinus. Perforation of the cortex may be noted in some cases and changes in the dentition are often observed. In addition, there is premature exfoliation of deciduous teeth and the permanent teeth may be missing, malformed, unerupted, or displaced (11). Hitomi and colleagues reported a case of cherubism in which resorption of the root apexes was not found (12). Our bone findings of perforation of the cortex and obliteration of the maxillary sinus are in agreement with Katz and Underhill (11). On the contrary, our patient did not demonstrate any tooth abnormalities $(11,12)$. The panoramic radiograph of our patient showed a bilateral multilocular lesion that involved the body and ramus of the mandible. The cortex was thinning and perforated in the ascending ramus of the mandible. Multiple loculi could be seen in both sides surrounded by a scalloped peripheral outline. The condyles were spared. In this case, the biopsy examination when associated to clinical and radiological findings was compatible with cherubism. Our case can be considered as being grade 3 (massive involvement of the whole maxilla and mandible, except the condyle processes) in the cherubism grading system proposed by Ramon and Engelberg (6).

Marck and Kudryk (13) reported that conventional radiography provided a limited image because it is only two-dimensional. On the other hand, CT provided a realistic picture of the lesions showing some aspects that otherwise would not be demonstrable due to superposition and the anatomical complexity of the jaws. The value of using supplementary CT for the diagnosis of cherubism is confirmed by the present report. CT can contribute to the diagnosis at all stages of cherubism and it can demonstrate other bones involved in the lesion that could not be reported in a conventional radiograph.

Bianchi and colleagues (15) studied six cases with CT scans. In two of these cases, they detected maxillary lesions that could not be seen on conventional radiographs. In all cases, both the maxilla and mandible were affected. They concluded that conventional radiography is sufficient for establishing a diagnosis of cherubism only in cases in which bone lesions are highly characteristic. CT gave useful information concerning the site, extension and components of the bone lesions in all stages of cherubism.

In our case, the CT showed a multilocular appearance in the mandible created by the presence of bone septa and expansion of both cortices and perforation in some places. Moreover, we noticed the involvement of both maxillas. The lesion expanded into the maxillary sinus but did not cause any involvement of orbital floor. On the other hand, the lesion affected the temporal bone. This finding was not found in the literature review.

In addition, several authors have reported that in spite of being a self-limiting condition that subsides with 
age, it can cause serious orbital abnormalities (14) and impairment of hearing (10).

In conclusion, we suggest that all cases of cherubism should be studied through CT because it can give much more information considering the extension and involvement of the bones, with a more specific spectrum of the lesion.

\section{RESUMO}

O querubismo é uma doença fibro-óssea benigna, hereditária, e que envolve maxila e mandíbula. Nós descrevemos um caso de uma menina de 10 anos de idade cuja radiografia panorâmica foi insuficiente para o diagnóstico da doença. Os achados clínicos, histológicos e radiográficos foram discutidos. Realizou-se, então, uma TC que não só confirmou o envolvimento de maxila e mandíbula mas também o comprometimento do osso temporal, o que não é visualizado em radiografias convencionais.

\section{REFERENCES}

1. Pindborg JJ, Kramer IRH, Torloni H. In: Histological Typing of Odontogenic Tumor, Jaw Cysts, and Allied Lesions. $1^{\text {st }}$ ed. Geneva: World Health Organization, 1971. p 18-19.

2. Peter WJN. Cherubism: A study of twenty cases from one family. Oral Surg Oral Med Oral Pathol 1979;47:307-311.

3. Anderson DE, McCledon JL. Cherubism - Hereditary fibrous dysplasia of the jaws. Part I - Genetic considerations. Oral Surg Oral Med Oral Pathol 1962;15:5-15.

4. Langlais RP, Langland OE, Nortjé CJ. Multilocular radiolucencies. In: Diagnostic Imaging of the Jaws. $1^{\text {st }}$ edn. Malvern: Williams and Wilkins, 1985. p 367-370.

5. Davis GB, Sinn DP, Watson SW. Cherubism: Clinicopathologic conferences. J Oral Maxillofac Surg 1983;41:119-120.

6. Ramon Y, Engelberg IS. An unusually extensive case of cherubism. J Oral Maxillofac Surg 1986;4:325-328.

7. Pulse CL, Moses MS, Greenmam D, Rosenberg SN, Zegarelli DJ. Cherubism: case reports and literature review. Dent Today 2001;20:100-103.

8. Timosca GC, Galesanu RM, Cotutiu C, Grigoras M. Aggressive form of cherubism: report of a case. J Oral Maxillofac Surg 2000;58:336-344.

9. Jones WA. Familial multilocular cystic disease of the jaws. Am J Cancer 1933; 17:946-50.

10. Ongole R, Pillai RS, Pai KM. Cherubism in sibilings: A case report. J Can Dent Assoc 2003;69:150-154.

11. Katz JO, Underhill TE. Multilocular radiolucencies. Dent Clin N Am 1994;38:63-81.

12. Hitomi G, Nishide N, Mitsui K. Cherubism: diagnostic imaging and review of the literature in Japan. Review. Oral Surg Oral Med Oral Pathol Oral Radiol Endod 1996;81:623-628.

13. Marck PA, Kudryk WH. Cherubism. J Otolaryngol 1992;21:8487.

14. Colombo F, Cursiefen C, Neukam FW, Holbach LM. Orbital involvement in cherubism. Ophthalmol 2001;108:1884-1888.

15. Bianchi SD, Boccardi A, Mela F, Romagnoli R. The computed tomographic appearances of cherubism. Skeletal Radiol 1987;16:6-10. 